\title{
OS MARCADORES DISCURSIVOS NA EDUCAÇÃO BÁSICA: NECESSIDADE DE SISTEMATIZAÇÃO A PARTIR DO LIVRO DIDÁTICO
}

\author{
LOS MARCADORES DEL DISCURSO EN LA EDUCACIÓN BÁSICA: NECESIDAD DE LA \\ SISTEMATIZACIÓN EN LOS LIBROS DE TEXTO
}

\author{
THE DISCOURSE MARKERS IN BASIC EDUCATION: \\ A NEED FOR SYSTEMATIZATION IN TEXTBOOKS
}

\author{
Bougleux Bomjardim da Silva Carmo* \\ Maria D'Ajuda Alomba Ribeiro* \\ Universidade Estadual de Santa Cruz - UESC, Ilhéus, BA
}

\begin{abstract}
RESUMO: Neste artigo, discutiremos a necessidade da sistematização dos marcadores discursivos na Educação Básica. Essa proposta emerge da pesquisa em andamento: "A sistematização dos conectores contra-argumentativos na concepção do material didático", realizada a partir das teorias pragmáticas em Portolés (1998), Alomba Ribeiro (2005), dentre outros. Os marcadores são unidades linguísticas com destacado papel no funcionamento da língua, na ação discursiva em textos orais e escritos e constituem-se como fenômeno importante da língua em uso. Todavia, sabe-se que o livro didático não aborda essa função pragmática de determinadas categorias gramaticais tradicionais que os compõem. Tendo isso presente, selecionamos, dentre os livros aprovados pelo PNLD 2014, a coleção Perspectiva: Português de Discini e Teixeira (2012) para verificação desses pressupostos. Como resultado de descrição e análise, apresenta-se uma atividade fonte ilustrativa com o marcador contra-argumentativo "mas" e seu uso em textos escritos.
\end{abstract}

PALAVRAS-CHAVE: Marcadores discursivos. Material didático fonte. Pragmática. Ensino.

RESUMEN: En este artículo vamos a discutir la necesidad de sistematización de los marcadores del discurso en la Educación Básica. Esta propuesta surge de la investigación en curso: "La sistematización de los conectores contra-argumentativos en el diseño del material didáctico", a partir de la teoría pragmática Portolés (1998), Alomba Ribeiro (2005), entre otros. Los marcadores son unidades lingüísticas con papel prominente en el funcionamiento del lenguaje, la acción discursiva en textos orales y escritos y representan un fenómeno importante de la lengua en uso. Además, se sabe que el libro de texto no aborda la función pragmática de determinadas categorías gramaticales tradicionales que los componen. En este orden de ideas, se seleccionaron a partir de los libros aprobados por PNLD 2014 la colección Perspectiva: Portugués de Discini y Teixeira (2012) para verificar estos supuestos. Como resultado de la descripción y análisis presentamos una actividad fuente ilustrativa con marcador contraargumentativo "pero" y su uso en textos escritos.

PALABRAS CLAVE: marcadores del discurso; material educativo fuente; pragmática; educación.

ABSTRACT: In this article, we will discuss the need for a systematization of discourse markers in Basic Education. This proposal emerges from the following ongoing research: "The systematization of contrastive connectors when devising textbooks", which departs from the pragmatic theories by Portolés (1998), Alomba Ribeiro (2005), and others. Markers are linguistic units with a prominent role in the functioning of language use. However, it is known that textbooks do not show the pragmatic function of certain traditional grammatical categories. So, we selected one out of the textbook collections approved by PNLD 2014, namely, the Perspective: Portuguese collection by Discini and Teixeira (2012) to verify these premises. As a result of the description and analysis we present a illustrative source activity with the discourse marker "but" and its uses in written texts.

KEYWORDS: discourse markers; source materials; pragmatic; teaching.

\section{INTRODUÇÃO}

Os livros didáticos da Educação Básica têm apresentado importantes contribuições da Linguística, especialmente objetos da Linguística de Texto e da Sociolinguística Variacionista, tal como nos apresenta Val

\footnotetext{
* Mestrando no Mestrado Profissional em Letras, UESC, Bahia. Tutor do curso de Letras Vernáculas - EaD / UESC, docente no Centro Universitário Leonardo Da Vinci, polo de Teixeira de Freitas, Bahia e docente da rede pública estadual de ensino da Bahia. Especialista em Metodologia do Ensino da Língua Portuguesa e em Linguística Aplicada pela Faculdade Vale do Cricaré (2014). E-mail: bug7raio@gmail.com.

* Professora do Mestrado Linguagens e Representações e do Mestrado Profissional em Letras, UESC, Bahia. Doutora em Linguística Aplicada pela Universidade de Alcalá (2005). E-mail: dajudaalomba@hotmail.com.
} 
(2008). De qualquer forma, inúmeros fenômenos da língua em uso continuam excluídos dos manuais didáticos, subjazendo a ideia de que o componente pragmático é constantemente negligenciado pela abordagem gramatical desses manuais. Essa realidade pressupõe que determinados objetos de estudos da Pragmática ainda carecem de verticalização, apresentação e didatização nos livros didáticos (doravante LDs). É neste contexto em que marcadores discursivos (doravante MDs) se encontram. Tal constatação parte da análise dos livros didáticos do Programa Nacional do Livro Didático - PNLD para o triênio 2014-2016. Ao que parece, ou essas coleções não abordam esse fenômeno da língua em uso, que precisa ser analisado considerando o componente pragmático da análise linguística, ou essa abordagem é incipiente.

Igualmente, é possível constatar que as classes tradicionais que compõem os MDs são apresentadas somente sob o enfoque da Gramática Tradicional (doravante GT) nesses livros didáticos. De fato, inúmeras unidades linguísticas não se encaixam nas definições da GT, dado o fato de, em geral, os manuais do ensino básico focalizarem o nível morfossintático da descrição linguística. O resultado muitas vezes vem a ser um conjunto de exceções que encontram pouca explicação e, portanto, não são abordados de forma abrangente.

Convém ressaltar que, na pesquisa ${ }^{1}$ em andamento, da qual esse trabalho emerge, as propostas estão em processo de amadurecimento, por conseguinte, tem-se como um dos objetivos o fomento, para a Educação Básica, de cadernos didáticos em uma proposta de sistematização da abordagem dos MDs, na defesa de um ensino gramatical produtivo que leve em consideração a dimensão do uso (TRAVAGLIA, 1997). Nessa perspectiva, deve-se apresentar e/ou problematizar o universo de funções, propriedades e características dos MDs nos textos escritos, apontando para as funções não previstas pela descrição tradicional.

Para tanto, será apresentado sucintamente o emolduramento teórico que permeia tal proposta, ilustrando-o com um recorte didático do que se pretende com projeto maior. No presente trabalho, apenas o MD contraargumentativo "mas" será analisado e didaticamente tratado como amostra dos procedimentos de didatização em processo de amadurecimento na pesquisa original. Tendo-se em conta que o fenômeno em estudo não se encontra descrito na GT, tornam-se necessárias propostas instrucionais para estas unidades, no suporte didático, que possam contribuir para dirimir essas contingências, dando condições aos estudantes de fazerem uso consciente e eficaz dos MDs na escrita de forma geral.

É importante ressaltar que essa abordagem dos MDs, na perspectiva pragmática², tende a alterar a forma de se abordar diversos conteúdos comumente trabalhados nas Séries Finais do Ensino Fundamental como, por exemplo, o estudo do período composto por coordenação e subordinação, a diferenciação entre conjunções e conectores, bem como o processo de argumentação e produção textual relacionado ao uso dos conectivos. É possível crer que a abordagem com os conectores, na perspectiva adotada nesse trabalho, possa contribuir para complementar a descrição tradicional presente nos manuais didáticos. Dessa maneira, favorecer o desenvolvimento da competência comunicativa dos estudantes.

Esse trabalho se organiza em quatro momentos. No primeiro momento, destaca-se o conceito dos MDs, dentro das hipóteses teóricas elencadas, sendo elementos que orientarão a abordagem gramatical e a proposição da atividade didática. São ressaltados quais os possíveis impactos desse fenômeno para o desenvolvimento da competência discursiva dos estudantes, nos termos de L. A. Oliveira (2010). No segundo momento, será apresentada uma breve problematização acerca do livro didático e como os estudos pragmáticos podem favorecer sua concepção. Na sequência, apontamos de forma sucinta como as conjunções adversativas são

1 A referida pesquisa intitula-se "A sistematização dos conectores contra-argumentativos na concepção do material didático" e investiga como se efetiva (ou não) o estudo dos conectores contra-argumentativos nos livros didáticos do Programa Nacional de Livro Didático das séries finais do Ensino Fundamental. Os referidos conectores formam uma subclasse de marcadores discursivos, conforme o quadro teórico apresentado nesse trabalho. No contex to do Mestrado Profissional em Letras e tendo em vista a sua natureza, a abordagem dessa pesquisa tem cunho prático e volta-se de forma direta ao ensino básico.

2 Para melhor entendimento de nossa abordagem, assumimos a expressão pragmática para o componente da descrição linguística referente aos usos feitos dos elementos fonológicos, morfossintáticos e semânticos (OLIVEIRA, 2010). Corresponde também à corrente teórica que considera essencial tratar o fenômeno linguístico dentro do contexto de uso (PORTOLÉS, 1998) e, no que tange à concepção do livro didático, remete-se à ideia de fazer uso de exemplos reais da língua e não somente da metalinguagem nos estudos gramaticais (ALOMBA RIBEIRO, 2005; MENDES 2012). 
apresentadas em um dos LDs do PNLD. Finalmente, na última etapa, apresentamos uma possibilidade de abordagem dos MDs com base na proposta de Mendes (2012).

\section{MARCADORES DISCURSIVOS: CONCEITUAÇÃO E DIDATIZAÇÃO}

Os MDs consistem uma classe gradiente de elementos linguísticos que desempenham papel fundamental na interação comunicativa, em textos orais e escritos, sendo partículas responsáveis por orientar a interação, guiar o processo inferencial e facilitar o processamento cognitivo de textos escritos, dentre outras funções. Corroborando com essas definições dos MDs, partindo da análise do português falado culto, por meio do projeto Nurc-Brasil, dentro da perspectiva dos estudos da Linguística Textual-Interativa, Risso, Silva e Urbano (2002) assim os definem com base na análise de corpus:

Trata-se de um amplo grupo de elementos de constituição bastante diversificada, envolvendo, no plano verbal, sons não lexicalizados, palavras, locuções e sintagmas mais desenvolvidos, aos quais se pode atribuir homogeneamente à condição de uma categoria pragmática bem consolidada no funcionamento da linguagem. Por seu intermédio, a instância da enunciação marca presença forte no enunciado, ao mesmo tempo em que se manifestam importantes aspectos que definem sua relação com a construção textual-interativa. (RISSO; SILVA; URBANO, 2002, p. 21 ).

Essa homogeneidade, como configura a proposta dos autores supracitados, forma-se a partir de um conjunto de traços definidores. É essencial frisar que a constituição desse núcleo definidor configura-se numa abordagem generalista do fenômeno, de sua natureza e propriedades. Porém não há efetivamente uma classificação dos elementos constituintes, de forma que os MDs (i) operam no plano da atividade enunciativa; (ii) asseguram a ancoragem pragmática; (iii) apontam as instâncias produtoras do discurso com a estruturação textualinterativa; (iv) manifestam um processo de acomodação do significado literal; (v) são independentes da estrutura sintática. A partir desse conjunto, verifica-se acentuado hibridismo na relação fala e escrita, uma vez que há marcadores que atuam com mais incidência na fala, outros na escrita e outros que ocorrem em ambas as modalidades. Na pesquisa em andamento, priorizam-se os MDs que tem atuação textual-interativa na modalidade escrita e aqueles MDs próprios da oralidade que influenciam o processo da escrita.

Na hipótese teórica definidora de Portolés (1998), elementos oriundos das diversas categorias (conjunções, advérbios e interjeições) compõem os MDs, estabelecendo seus usos e relações tanto na orientação das inferências, na coesão frasal, na sequenciação e nos encadeamentos discursivos. Pressupondo a comunicação como um processo essencialmente inferencial, os MDs seriam unidades linguísticas que condicionam o processamento do discurso em relação ao contexto, constituindo-se em signos de processamento, tendo um significado de uso e não propriamente conceitual. Assim, com base na abordagem das teorias Pragmáticas desse autor, os MDs são conceituados como:

Unidades linguísticas invariáveis que não exercem uma função sintática no marco da predicação oracional e possuem uma tarefa correspondente no discurso: o de guiar, de acordo com suas distintas propriedades morfossintáticas semânticas e pragmáticas, as inferências que se realizam na comunicação. (PORTOLÉS ${ }^{3}$, 1998, p. 25-26).

Trata-se de um fenômeno determinante ao funcionamento da língua e vale-se dos demais componentes / níveis linguísticos para sua realização. Contudo, os MDs necessitam serem considerados mediante o nível pragmático da descrição linguística. Portolés (1998), além de levantar os critérios para definição, propõe a classificação relativa aos elementos. Interessante lembrar que os MDs também são objetos de estudo de diferentes áreas, a saber: da Linguística Textual, da Análise da Conversação, da Sociolinguística Interacional e, no caso deste artigo e da pesquisa que o fundamenta, da Pragmática. Constituem-se funções dessas unidades a atuação no direcionamento inferencial da comunicação humana como um todo, bem como na concatenação da construção

\footnotetext{
${ }^{3}$ Los marcadores del discurso son unidades linguísticas invariables, no ejercen una función sintáctica en el marco de la predicación oracional e poseen um cometido coincidente em el discurso: el de guiar, de acuerdo com sus distintas propiedades morfosintácticas, semânticas y pragmáticas, las inferencias que se realizan en la comunicación. (PORTOLÉS, 1998, p. 25-26).

Forum linguistic., Florianópolis, v.11, n.4, p.457-473, out./dez.2014.
} 
de sentenças e situações discursivas complexas na modalidade escrita, no direcionamento dos processos de argumentação e na facilitação do processamento cognitivo dos textos escritos, nos termos de Morais (2011).

Tendo em vista a diversidade de estudos acerca do fenômeno, convém ressaltar que esse trabalho se apoia na classificação proposta por Portolés (1998), bem como na orientação terminológica considerada mais ampla. Nessa perspectiva, os MDs distribuem-se em cinco categorias radiais, quais sejam: os estruturados da informação, os conectores, os reformuladores, os operadores discursivos e os marcadores de controle de contato (PORTOLÉS, 1998, p. 146). Essas categorias maiores possuem suas subdivisões. Para nosso trabalho, a classe dos conectores divide-se em aditivos, consecutivos e os contra argumentativos. O signo "mas" encontra-se nessa última subcategoria mencionada.

Quanto à função de facilitador do processamento cognitivo, Morais (2011) aborda que o papel destas unidades se efetiva dando pistas que ativam operações cognitivas que conduzem à compreensão, evidenciado as relações discursivas, ajudando a reduzir o esforço empregado à compreensão e facilitando ainda que as intenções do autor se evidenciem. A ausência dos MDs exige maior esforço no processamento da compreensão para alcançar as inferências e a representação discursiva como um todo, uma vez que funcionam como instruções facilitadoras da interpretação, pois são sinalizadores das relações nas quais os segmentos discursivos do tex to estabelecem, contribuindo para estabelecer a representação de coerência do texto.

Todo esse aporte nos leva a refletir acerca de benefícios e possíveis impactos da pesquisa com os MDs no contexto da Educação Básica. É possível crer que a didatização desse fenômeno possa contribuir sobremaneira ao desenvolvimento da competência comunicativa dos estudantes. Essa crença nos é estimulada por S. D. J. Silva (2004) ao afirmar que o não tratamento dos marcadores no ensino de Língua Portuguesa priva o estudante do conhecimento do papel dos operadores argumentativos, uma vez que estes são responsáveis por garantir a coerência das mensagens, bem como gerenciar a conversação, além disso, esses operadores são comuns no discurso. Seu estudo justifica-se por trazer a este público estratégias que o falante pode usar para que a comunicação seja bem sucedida, e isso também é operacionalizado pelos MDs.

Embora o enfoque dessa pesquisa não seja os fatos da oralidade, percebemos que mesmo no gênero escrito inúmeras funções são correlatas entre as duas modalidades. Assim, a coerência, a coesão e o gerenciamento de ideias no texto escrito também dependem do uso adequado dos MDs. Torna-se relevante ainda discutir como se abordar de forma significativa esses signos de processamento (PORTOLÉS, 1998), levando em consideração a língua em uso e ampliando a descrição destas unidades para o enriquecimento de seu emprego. Entendemos que com o estudo dos MDs pode-se favorecer o domínio discursivo ${ }^{4}$, a capacidade de agir pela linguagem escrita, bem como ajudar os estudantes a processarem e conduzirem a própria linguagem e o próprio discurso de maneira mais consciente, coerente, eficaz e abrindo espaços para o desenvolvimento de novas habilidades e abordagens das categorias gramaticais tradicionais (BRASIL, 1998).

Quanto à importância dessa proposta de pesquisa, Freitag (2007) endossa que os MDs não são reconhecidos como uma categoria na gramática normativa e, por conseguinte, "não aparecem nos materiais didáticos, nem constam nos currículos escolares, sendo cercados de estigma social” (FREITAG, 2007, p. 28). Sabe-se que o estudante faz uso destas partículas tanto na fala quanto na escrita de forma intuitiva, como bem sinaliza Portolés (1998, p. 13). Esse uso intuitivo se deve à carência na descrição do fenômeno nas gramáticas e, consequentemente, de sua abordagem no ensino de língua como um todo.

Partindo das definições apresentadas, percebe-se que há uma necessidade real dessa proposta no contexto aqui apresentado. Urge dar condições aos estudantes da escola pública de manipularem esses recursos fundamentais ao funcionamento da língua. De forma que é no livro didático o ponto de partida para essa sistematização, questão fundamental ser tratada na seção seguinte, bem como o papel da Pragmática, enquanto orientação

\footnotetext{
${ }_{4}^{4}$ Domínio discursivo nesse trabalho tem relação com a capacidade de concatenar ideias por meio do uso dos conectores discursivos, favorecendo progressão e encadeamento de ideias no texto escrito, tal como nos indica Montolío (2001, p. 21) "señalar de manera explícita com qué sentido van encadenándose los diferentes fragmentos oracionales del texto para, de esa manera, ayudar al receptor de um texto guiándole en el processo de interpretación”.
} 
teórica e metodológica para concepção e complementação dos estudos gramaticais dos livros e manuais didáticos.

\section{LIVRO DIDÁTICO, PRAGMÁTICA E DIDATIZAÇÃo DOS MDS}

O LD deve ser uma preocupação constante por parte de todos os envolvidos com as questões do ensino de língua materna e das pesquisas linguísticas funcionalistas. Segundo dados apresentados por Tokarnia (2013), da Agência Brasil, em levantamento feito pela ONG QEdu: Aprendizado em Foco no site da $\mathrm{EBC}^{5}$, o LD ocupa o segundo lugar dentre os mais lidos no Brasil, perdendo somente para a Bíblia. Informa-se ainda que $98 \%$ dos professores da Educação Básica usam LDs, sendo que do restante, 1\% acredita não ser necessário seu uso e 1\% não o faz porque não há o material disponível na escola. No texto do site, a professora da Faculdade de Educação da Universidade de São Paulo (USP), Circe Fernandes Bittencourt, ainda comenta que o livro didático permanece como sendo a ferramenta e o referencial educativo central de alunos e professores. Portanto, as nossas reflexões estão em consonância com essa realidade.

No contexto do ensino público, o Fundo Nacional de Desenvolvimento da Educação (FNDE), por meio do Programa Nacional do Livro Didático (PNLD), é o responsável pela aquisição e pela distribuição dos livros. Verificando os dados do FNDE, em relação à aquisição e à distribuição integral de livros em 2014 por meio de altos investimentos, observa-se um total de 31.102.628 alunos atendidos e 137.858.058 de livros distribuídos. Tal quantitativo merece atenção e análise cuidadosa, no sentido de que a proposta de sistematização dos MDs pode impactar nesse contexto, ou seja, o conteúdo presente no manual didático é objeto de mediação cognitiva, uma vez que esse suporte influencia de forma determinante na seleção de conteúdos, nos procedimentos metodológicos e, principalmente, nas questões conceituais, podendo obstruir a construção de novos significados e mesmo a autonomia docente, como endossa Dávila (2013).

Outro fator, que não deixa a questão do LD ser negligenciada, advém de pesquisa realizada, em 2013, pela Associação Brasileira de Autores de Livros Educativos (ABRALE), que aponta para o fato de que os jovens preferem ler livros em papel; ao passo que o formato digital, os e-books, foram preferidos por apenas $38 \%$ dos entrevistados. Tendo em vista esse contexto, interessa-nos investigar, nas coleções aprovadas pelo programa e que compõem o corpus da pesquisa que fundamenta esse trabalho, o fenômeno dos marcadores.

A partir da apresentação desses dados, fica subjacente a ideia de que os conteúdos de Língua Portuguesa elencados nessas coleções terão um impacto maior no contexto do ensino e precisamos investigar se o nosso objeto de estudo é abordado (ou não) e de qual forma. A coleção analisada nesse trabalho está entre as dez coleções mais vendidas em todo território nacional. Esses e outros pressupostos ratificam a escolha desse instrumento pedagógico como alvo da pesquisa com os MDs. Para L. A. Oliveira (2010), desenvolver a competência discursiva constitui-se como um objetivo do ensino de língua materna, pois o ensino gramatical deve visar além do conhecimento metalinguístico da língua, o uso em situações diversas e concretas.

Como se vê, existe um contexto social e político que envolve a questão do uso do LD, inclusive pautado pela legislação e pela participação de diversas entidades da sociedade civil. Em suma, os dados nos mostram que os conteúdos veiculados nos livros distribuídos em larga escala impactam de forma mais significativa nesse mesmo contexto. Igualmente, a abordagem desses conteúdos segue determinadas linhas teóricas, de maneira que defendemos a integração do componente e da dimensão pragmática na concepção do material didático relativos aos estudos dos MDs.

Convém, ainda, esclarecer, aqui, como os estudos da Pragmática podem conquistar espaço nesse contexto, no qual o LD se encontra. L. A. Oliveira (2010), sinaliza para a importância do enfoque pragmático ao nos lembrar de que o estudante já sabe falar português e se vale desses conhecimentos intuitivos da oralidade para aplicar ou

\footnotetext{
${ }^{5}$ A Empresa Brasil de Comunicação S.A - EBC é uma empresa pública, constituída por capital fechado sob a forma de sociedade anônima, associada à Secretaria de Comunicação Social da Presidência da República, com fins à prestação de serviços de radiodifusão e serviços conexos públicos, instituída pelo Decreto $\mathrm{N}^{\mathrm{o}}$ 6.689, de 11 de dezembro de 2008. Disponível em: <www.ebc.com.br>. Acesso em: 04 maio 2015.

Forum linguistic., Florianópolis, v.11, n.4, p.457-473, out./dez.2014.
} 
construir os conhecimentos da escrita, ressaltando ainda que as duas modalidades tenham suas especificidades, mas há pontos de contato, portanto:

[...] a escrita dos estudantes de português tende a ser marcada por características da fala. Isso é absolutamente normal. Cabe ao professor ajudá-los a diminuir essa tendência, informando-lhes que não escrevemos como falamos e nem falamos como escrevemos, embora a presença de marcas orais na produção escrita dos alunos seja um fenômeno absolutamente normal e esperado. (L. A. OLIVEIRA, 2010, p. 110).

Além desses fatores, existe uma acentuada influência da oralidade sobre as redações escolares, nas quais os alunos acabam por transpor traços da fala na produção escrita, de forma que:

Os alunos tenderão a usar os marcadores discursivos nos textos formais da escrita, por não conseguirem diferenciar os aspectos específicos dos diferentes gêneros textuais da fala e da escrita; e por não estarem familiarizados com as estratégias de processamento de determinados gêneros formais da escrita, os alunos utilizarão os marcadores discursivos com finalidade coesiva. (I. G. OLIVEIRA, 2012, p.12).

A referida autora aponta que a multifuncionalidade dos MDs permite seus usos nos vários gêneros realizando a articulação discursiva de modo a facilitar o processamento do texto por parte de leitor. A nosso ver, o conhecimento desse espectro de funções pode ajudar o estudante a realizar um uso menos intuitivo desses elementos, levando em conta que os MDs estejam no interstício fala/escrita. Entendemos ainda que o docente necessita ter, no material didático que utiliza, essas prerrogativas teóricas e os recursos necessários para fazer suas intervenções. $\mathrm{O}$ fenômeno dos marcadores não pode estar à margem do ensino; ao contrário, é preciso colocá-lo em destaque para que essa consciência discursiva seja desenvolvida pelo seu uso adequado.

Segundo S. D. J. Silva (2004, p. 80), "privar o aprendiz de tais instrumentos é tornar ineficiente e incompleto o processo de aquisição das competências discursivas, comunicativa e pragmática”. Esse autor explica ainda que as contribuições e as investigações da Pragmática podem servir como "instrumento útil ao desenvolvimento de materiais que melhor reflitam a língua portuguesa em seu uso efetivo dentro de um contexto sociocultural" (2004, pp. 35). Importa frisar que os MDs têm forte impacto sobre o planejamento da produção textual, atuando por meio de suas funções textuais e interativas. Nessa perspectiva, L. A. Oliveira (2010) entende que a produção textual é um processo que necessita de planejamento para sua execução, de forma que o uso adequado dos MDs tende a garantir coesão, coerência e desenvolvimento discursivo do texto.

Em contraponto à abordagem tradicional, a ancoragem pragmática pode ampliá-la, conforme apresenta o referido autor ao se reportar ao ensino de conjunções e locuções conjuncionais (uma das categorias que compõem os MDs):

Tradicionalmente, os professores costumam fazer os estudantes focarem a atenção na nomenclatura gramatical quando abordam as conjunções: subordinativas, coordenativas [...] Para o ensino da escrita, a nomenclatura é irrelevante - o que importa mesmo é o aluno saber o que as conjunções significam para ser capaz de conectar ideias nos textos. (L. A. OLIVEIRA, 2010, p. 137).

Interessante observar que elementos que são objetos de estudo particularmente da Linguística de Texto, tais como a intencionalidade, a aceitabilidade (elementos da textualidade), bem como as estratégias de argumentação, coesão, coerência e o estudo dos períodos compostos são fenômenos linguísticos que sofrem influência da atuação dos MDs. Para esse autor, o mais importante é conhecer a funcionalidade das categorias exercida nos textos lidos e produzidos em sala de aula.

Tendo em vista essas considerações, uma das hipóteses que a pesquisa levanta refere-se ao fato da abordagem gramatical dos LDs não considerar a dimensão pragmática destes elementos voltada para o trabalho com os textos escritos. Nessa acepção, é preciso analisar os usos dos elementos linguísticos em contextos reais de interação. Dessa forma, além do componente fonológico, morfossintático e semântico, é preciso considerar o nível pragmático para complementar a análise, a descrição e o uso linguístico, conforme sinaliza L. A. Oliveira (2010). 
Além desses fatores, Freitag (2007) afirma que muitas marcas da oralidade são estigmatizadas por faltar à devida sistematização ou prescrição gramatical. Nesse caso, cremos que seja importante debater a questão da instrução desses MDs, chamado pela referida autora de pontuantes e classificados como "controle de contato" em Portolés (1998). Entendemos que determinadas categorias orais dos MDs (tais como aí, então, né, mas, dentre outros), presentes nos textos escritos e oriundos da oralidade, precisam ser analisadas de forma coerente com suas funções textuais, interativas, discursivas e como o uso as condiciona. Essa didatização pode propiciar aos discentes o uso consciente e adequado dessas partículas, em especial na produção de textos escritos, uma vez que tais marcadores influenciam sua escrita. Nessa mesma linha, é necessário que haja instrução acerca do fenômeno para que os estudantes tenham condições de refletir sobre o uso dessas partículas. Todos esses fatores resultam na necessidade de uma análise linguística na perspectiva accional, em outros termos:

A pedagogia das línguas em geral e da língua materna em particular só tem a ganhar quando integra no seu seio uma teoria linguística alargada à pragmática, isto é, que não separa os enunciados do seu quadro situacional e que considera a análise do comportamento verbal como inseparável a análise do comportamento em geral. (J. M. SILVA, 2006, p. 17).

Podemos afirmar que a concepção de materiais didáticos não pode prescindir desses valores, uma vez que a perspectiva discursivo-pragmática do ensino de língua "implica, sobretudo uma forma de tratamento desses discursos que leve o aluno à compreensão e apropriação do seu funcionamento, apropriação que possa ser garantia da aquisição de uma competência discursiva” (J. M. SILVA, 2006, p. 17).

Em suma, a postura ou a proposta adotada por vários autores está em sintonia com essa proposta de trabalho em garantir o nível pragmático na descrição e no uso dos elementos linguísticos, partindo da necessidade de se ter no principal suporte didático da Educação Básica, no caso o livro, o estudo dos conectores na perspectiva aqui apresentada. Convém lembrar que os MDs constituem-se numa categoria que se efetiva no nível do uso, valendo-se de diversas unidades lexicais oriundas das diversas classes morfológicas tradicionais, especialmente conjunções, interjeições e advérbios. Considerando a pouca extensão deste trabalho, a análise realizada ateve-se a uma coleção do PNLD 2014 e à classe das conjunções adversativas.

\section{METODOLOGIA: ABORDAGEM DAS CONJUNÇÕES EM UM LD DO PNLD}

A descrição da coleção Perspectiva: Português (Volumes 08 e 09 do Ensino Fundamental) de Discini e Teixeira (2012) tem como objetivo investigar como se dá (ou não) a abordagem dos MDs. Em outras palavras, pretendese constatar se a conjunção adversativa "mas" é trabalhada apenas em suas funções prototípicas, ou se são apresentadas outras funções advindas do uso dessa unidade, de maneira que as conjunções adversativas têm sua conceituação definida pela GT. Aqui destacamos tais conjunções como amostra ilustrativa.

Esse trabalho e a pesquisa que o ancora centram-se na análise de livros didáticos dos oitavos e nonos anos, anos finais do Ensino Fundamental, portanto. Nessa etapa do ensino básico, parte dos estudos linguísticos e/ou gramaticais tem relação com a classificação tradicional das classes morfológicas.

\section{RESULTADOS, ANÁLISES E DESDOBRAMENTOS}

\subsection{ANÁLISE DOS DADOS}

Em primeiro lugar, Discini e Teixeira (2012, p. 284) apresentam o conceito das orações coordenadas como sendo sintaticamente independentes, posto que uma não exerça função da outra, estão justapostas; porém, uma acrescenta sentido à outra. De forma que a conjunção "mas" é utilizada apenas para "unir orações". Tal conceito apresentando está em consonância com a GT. Entretanto, na obra não são apresentadas as conjunções (e seus respectivos conceito e uso em determinadas relações lógico-semânticas) e os conectivos básicos que orientam as principais relações de coordenação. 
De todo modo, conjunção adversativa "mas" e similares (contudo, todavia, entretanto) são trabalhadas estabelecendo relações com o processo de argumentação, no entanto, apenas a relação de oposição é utilizada para realizar réplicas de argumentação (DISCINI; TEIXEIRA, 2012, p. 289). Assinalam ainda que "conector mas liga ideias adversas, contrárias. Com isso, dá início a um novo tema, uma nova ideia, abre um novo cenário no texto" (DISCINI; TEIXEIRA, 2012, p. 118). Apesar de a obra apresentar um trabalho com a oralidade, não há nenhum dispositivo ou protocolo realizando conexões entre o estudo feito com as adversativas e o estudo ou a realização de gêneros orais. Além disso, a classificação das relações lógico-semânticas fica limitada àquela apresentada pela GT, dessa forma, não se apresenta sua função de MD conector contra-argumentativo.

Essa sucinta descrição deixa evidente que os conceitos tradicionais não são ampliados. A conjunção "mas" assume apenas a função adversativa em estabelecer relação de oposição e contrariedade argumentativa no nível do enunciado justapondo orações. Isso sinaliza para o fato de que as funções de MD dessa e das demais conjunções não são trabalhadas no ensino fundamental. Bechara (2004) define o papel da conjunção (conector ou transpositor) consiste em reunir orações num mesmo enunciado. Sendo as coordenadas pertencentes ao mesmo nível sintático e independentes ou pode "conectar" unidades menores em uma oração, sendo subordinada assinalaria a possibilidade de a oração ser sozinha, daí ser considerado um transpositor de um enunciado que passa a uma função de palavra, estabelecendo a subordinação. Assim apresenta o conceito para as conjunções adversativas:

Enlaçam unidades apontando uma oposição entre elas. As adversativas por excelência são mas, porém e senão. Ao contrário das aditivas e alternativas, que podem enlaçar duas ou mais unidades, as adversativas se restringem a duas. Mas e porém acentuam a oposição, senão marca a incompatibilidade […] (BECHARA, 2004, p. 321).

Fica clara a consonância entre os conceitos da GT em Bechara (2004) e do estudo gramatical dos volumes descritos. Essa consonância aponta-se no sentido de manter a classificação tradicional para os períodos compostos e para as conjunções, sem ampliação ou consideração das questões do uso. Conforme Alomba Ribeiro (2005), além do papel morfossintático de conjunção adversativa, a partícula "mas" funciona no plano discursivopragmático como um MD contra-argumentativo, com diversas funções e usos diferenciados.

Alomba Ribeiro (2005) atesta que além da função de oposição ou contraste, o "mas" assume as funções de compensação, de comparação, descompensadora, de inclusão, interativa conversacional, de objeção, pragmática, de superação e de justificativa. Como também, explana-se, por meio de exemplos de uso real da língua, que o conceito tradicional não dá conta desses desdobramentos que se realizam no uso que é feito das unidades linguísticas. De forma que, no plano discursivo, a conjunção "mas" assume papel de MD estabelecendo novas relações. Neves (2000) apresenta especificações dos valores semânticos desse conectivo, que além da função opositiva, pode assumir funções tais como de marcação de compensação com ou sem gradação, marcação de restrição por acréscimo, negação de inferência, contraposição por comparação, por eliminação, além de outros usos que a autora explana, embora não rotule com terminologia específica.

Na seção seguinte, abordamos os pressupostos que embasam a concepção das atividades anexas a esse trabalho. Tais proposições objetivam abordar a multifuncionalidade do MD "mas" e, dessa forma, ampliar a descrição da GT e a aplicação das funções não prototípicas da conjunção adversativa ou MD contra-argumentativo "mas".

\subsection{PROPOSTA DE ABORDAGEM PARA O MD “MAS”}

Para ilustrarmos o objeto em que nossa pesquisa trabalha, usamos como amostra a multifuncionalidade do conector contra-argumentativo "mas", segundo a abordagem de Alomba Ribeiro (2005), Neves (2000), Montolío (2001) e da classificação dos MDs proposta por Portolés (1998), dentre outros pressupostos teóricos para a compreensão dessa multifuncionalidade. A formatação da atividade concomitante baseia-se nos estudos proposicionais de Mendes (2012), L. A. Oliveira (2010), Bono (2009), S. D. J. Silva (2004) para a formatação do modelo de atividade apresentada.

Segundo Mendes (2012), o aprendizado de uma língua deve considerar a questão da interculturalidade, entendida como um esforço de integração que orienta o respeito ao outro, às diferenças e diversidades que 
caracteriza o processo de ensino-aprendizagem de qualquer conteúdo escolar. Segundo essa autora, é necessário incentivar os aprendizes a reconhecerem a língua em suas especificidades, não só formais, mas sobretudo culturais e contextuais (MENDES, 2012), de modo que a produção dos materiais e a seleção de conteúdos possam trazer exemplares da língua para se viver a interação.

Com base nestes breves postulados, nossa agenda de pesquisa amadurece a proposta de sistematização no modelo explorado pela referida autora, a saber, materiais fonte (source materials). Nesse tipo de material, a preocupação maior está na forma como o estudante pode agir e interagir com os dados, representando um conhecimento em potencial que se deseja ser internalizado, tendo uma estrutura flexível que pode se adaptar aos contextos a serem experimentados, sendo este o ponto de ancoragem central e:

[...] sem objetivar predizer ou predeterminar o que deve ou não ser considerado adequado para a aprendizagem. Eles possibilitam variadas formas de planejamento de lições, atividades e tarefas, promovendo insumos variados, em diferentes níveis de dificuldades e em diferentes quantidades, deixando o professor livre para aproveitá-los de acordo com as necessidades e oportunidades concretas vivenciadas em sala de aula. (MENDES, 2012, p. 364-365).

A questão da concepção do material didático merece um espaço mais abrangente de discussão que aqui não cabe. Contudo, tal material deve servir como suporte, apoio e fonte de recursos a fim de se construir a interação com a língua em uso, a língua-alvo. $\mathrm{O}$ aspecto pragmático deste tipo de material está na necessidade de ter nele amostras de língua representativas da linguagem real em uso, da língua usada em diversas situações sociocomunicativas.

Importa ressaltar que esse modelo de material e/ou atividade permite maior flexibilidade por parte da ação docente, bem como tem por finalidade complementar a descrição gramatical presente nos LDs de Língua Portuguesa, ao passo que didatiza a abordagem dos MDs. Igualmente, a escolha das temáticas busca estar em consonância com os Parâmetros Curriculares Nacionais, precipuamente os temas transversais e a pluralidade cultural.

Nessa perspectiva, é importante destacar que a abordagem da língua em uso, em consonância com os PCNs (1998), pressupõe o trabalho com as diversas formas da língua tanto na oralidade quanto na escrita, de forma que é preciso dispor de ações didáticas que possam metodologicamente aplicar as diversas manifestações da língua materna, ou seja, a linguagem verbal como prática social e discursiva precisa receber o tratamento adequado para que os estudantes possam expandir seus usos de forma consciente na escrita, o que já domina em alguns gêneros informais da modalidade oral. Ademais, o trabalho docente deve estar em consonância com os objetivos dos PCNs, desenvolvendo as habilidades básicas como ouvir, falar, ler e escrever. Em síntese, tal como definido nos PCNs (1998), é preciso partir do uso da linguagem para dominar novas habilidades linguísticas, no sentido de práticas de interlocução e didatizações que levem o aluno a refletir, não somente sobre a língua, mas também, sobre os usos da linguagem em diversos contextos e por propósitos definidos.

Sob essa ótica, é importante que o tratamento didático dos MDs, e, em nosso caso, do MD contraargumentativo "mas", também esteja relacionado com a matriz de referência de Língua Portuguesa para o tratamento dos diferentes usos da língua propostas pela Prova Brasil ${ }^{6}$ (BRASIL, 2008), no sentido de aliar o desenvolvimento das aptidões básicas por meio de habilidades e competências previstas pela matriz a serem desenvolvidas em sala de aula.

Nesse sentido, nosso trabalho converge com a proposta do MEC (BRASIL, 2008), por meio do uso dos descritores específicos para o tratamento do MD contra-argumentativo "mas", a saber, os descritores 12 e 15,

\footnotetext{
${ }_{6}^{6}$ Trata-se de um instrumento que mede as competências de leitura e matemática para os estudantes do quinto e nono anos, com periodicidade de dois anos. Constitui em um teste com base em itens em uma escala pré-definida. Esse teste é entendido como uma medida de garantia do direito ao aprendizado da leitura por meio da padronização e medição. Nesse sentido é uma forma de avaliar a educação básica brasileira e detectar de forma precisa onde estão as deficiências na aprendizagem (BRASIL, 2008).

${ }^{7}$ Conforme Brasil (2008), os descritores são elementos que indicam as habilidades avaliadas em cada tópico da Prova Brasil e estão relacionados à dimensão das competências que compõem a Matriz de Referência. Igualmente, os descritores estão dispostos em ordem crescente de aprofundamento das habilidades no tópico que integram.

Forum linguistic., Florianópolis, v.11, n.4, p.457-473, out./dez.2014.
} 
que indicam o estabelecimento de "relações lógico-discursivas presentes no texto, marcadas por conjunções" (BRASIL, 2008, p. 22). Esses descritores trabalham com o processamento do texto; os descritores 03 e 04, que, ao trabalharem procedimentos de leitura, pressupõem "inferir o sentido de uma palavra ou expressão" e "inferir uma informação implícita no texto” (BRASIL, 2008, p. 22) respectivamente. É justamente nas relações inferenciais e de processamento de relações lógico-discursivas que os MDs atuam, dentre outras funções.

\section{PROPOSTA ILUSTRATIVA PARA ABORDAGEM DO MD CONTRA-ARGUMENTATIVO “MAS”}

\subsection{BREVES CONSIDERAÇÕES}

Constituindo-se em atividades fontes dentro do modelo proposto por Mendes (2012) e Bono (2009), o professor de Língua Portuguesa pode valer-se da presente abordagem de forma flexível, no sentido de complementar a abordagem descritiva da unidade lexical em estudo. Igualmente, as atividades foram pensadas para os Anos Finais do Ensino Fundamental, oitavo e nono anos. A abordagem visa menos à metalinguagem e mais a reflexão nos usos. Todavia, as propostas não abordam todas as funções de MD possíveis para a conjunção "mas" e constituem apenas uma amostra das proposições em amadurecimento na pesquisa em desenvolvimento que ancora o presente trabalho. Portanto, as proposições aqui postas não apresentam caráter conclusivo. Nesse sentido, convém ressaltar que não existem receituários, mas propostas de didatização frente às problemáticas encontradas no contexto estudado.

Importa lembrar que as fontes das propostas são específicas e não constam nas referências do presente artigo; contudo, estão presentes no corpo das atividades, simulando uma diagramação habitual aos manuais didáticos da Educação Básica. A abordagem gramatical, sob o enfoque pragmático, segue também a proposta de Travaglia (1997), numa perspectiva reflexiva. Nesse sentido, o discente deve ser levado a refletir não somente nos fatos que já domina, mas também nos recursos linguísticos que ainda não domina (TRAVAGLIA, 1997, p. 142), constituindo-se um processo metodológico de ensino gramatical. Igualmente, busca-se focalizar "os efeitos de sentido que os elementos linguísticos podem produzir na interlocução” (TRAVAGLIA, 1997, p. 150). Nesse sentido, a preocupação gira em torno de como se atua com a língua e não com classificações, ajudando o discente a ter consciência em suas escolhas e a usar os recursos linguísticos com mais segurança e precisão.

Como qualquer conteúdo curricular, é necessário que se proceda a uma abordagem prévia, diagnóstico dos conhecimentos prévios, com a contextualização temático-metodológica e outras estratégias de preparação. Em suma, nenhuma atividade fonte terá sentido ou poderá alcançar os objetivos determinados se utilizada de forma descontextualizada e estanque. De qualquer forma, em termos de concepção e didatização, não se busca o apagamento conceitual tradicional, mas o equilíbrio entre a classificação tradicional e demais funções desempenhadas, como bem nos aponta Dias (2003, p. 136) ser "possível à realização de um trabalho com gramática na escola a partir de outras fontes de conhecimento da língua alternativas à gramática tradicional”. Segundo esse autor, o livro didático tem um importante papel na formulação de orientações seguras ao professor.

Portanto, pensar na concepção de materiais didáticos, atividades e estratégias metodológicas deve obrigatoriamente levar em consideração as concepções de língua, a visão que se tem ou se toma do objeto de ensino e, concomitantemente, nos impactos sociais, políticos e naqueles diretamente relacionados ao processo de ensino-aprendizagem e dos conteúdos curriculares (SUASSUNA, 2004). Em nossa proposta de trabalho, a perspectiva pragmática é um importante complemento à abordagem do ensino de língua portuguesa, a partir das orientações pressupostas no material didático como ponto de partida para a sistematização de um dado fenômeno linguístico.

\subsection{PROPOSTA8 ILUSTRATIVA I: ALGUMAS FUNÇÕES DO “MAS”}

\footnotetext{
${ }^{8}$ É importante ressaltar que a abordagem dessa atividade parte de um movimento interno que considera a conceptualização tradicional para em seguida apresentar as demais funções do objeto em estudo. Nessa perspectiva, os exercícios partem das funções prototípicas para, em seguida, abordar funções não prototípicas.
} 
TEXTO I - Tira

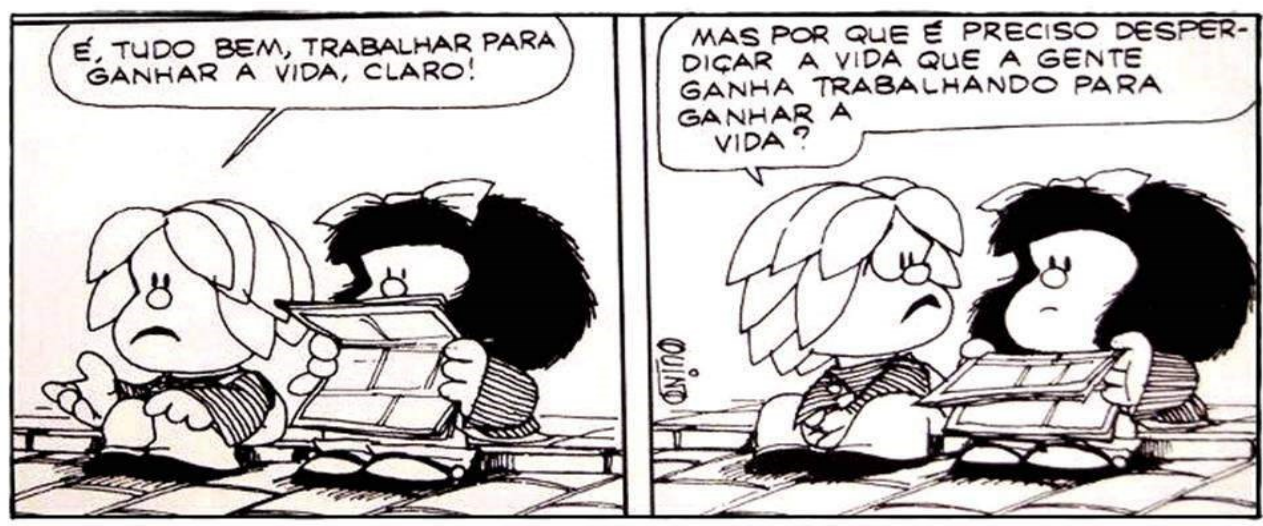

Fonte: <http://mundodesalienado.wordpress.com/>. Acesso em: 24 mar. 2014.

TEXTO II - Fiscalização falha dificulta combate ao trabalho infantil nos municípios de fronteira dos extremos Norte e Sul do Brasil ${ }^{9}$ por Stefano Wrobleski

Mais de 4 mil quilômetros separam o município amapaense de Oiapoque, no extremo Norte do Brasil, do Chuí, município gaúcho no extremo Sul. Os dois estão nos limites territoriais brasileiros: enquanto no Oiapoque um rio separa a população da Guiana Francesa, os habitantes do Chuí estão a uma rua de distância da vizinha uruguaia, que tem quase o mesmo nome: Chuy. Além de serem pontos extremos do país, o trabalho infantil e a falta de fiscalização - sempre mais eficiente do lado de lá da fronteira - são realidades que aproximam locais tão distantes.

No Chuí, uma força-tarefa realizada no início de novembro pelo Ministério do Trabalho e Emprego (MTE) e pelo Ministério Público do Trabalho (MPT) detectou diversas irregularidades trabalhistas, além de crianças e adolescentes trabalhando com o empacotamento dos produtos comprados pelos clientes nos supermercados da cidade. O Conselho Tutelar do município contabilizou, na época, que quase todos os cerca de 50 jovens trabalhando no Chuí "faziam caixinha", como é conhecida a atividade pela qual os consumidores pagam com esmolas.

A presidenta do Conselho Tutelar, Sonia Caetano, explica que há uma naturalização do trabalho infantil: "As pessoas acham que é melhor estar trabalhando do que fazendo outra coisa, porque pensam que as crianças estariam nas ruas se não fosse isso". Ela conta do caso de um homem que buscava emprego na cidade acompanhado de seu filho, de oito anos: "O dono [de um supermercado] disse a ele: "pra ti eu não tenho, mas tu deixas o teu filho aqui que ele pode fazer caixinha”. [ [...]

Para a realização das atividades ${ }^{10}$ discursivas a seguir, refletindo sobre o tema principal, leia e compreenda os textos acima.

1. Estabeleça os elementos constituintes de cada texto:

a. Qual o gênero de cada texto?

b. Em qual âmbito social esses textos são utilizados?

c. Qual a intenção central dos textos apresentados?

d. Quem seriam os receptores desses textos, ou seja, a quem eles são dirigidos?

\footnotetext{
${ }_{9}^{9}$ Disponível na íntegra em: <http://reporterbrasil.org.br/trabalhoinfantil/do-oiapoque-ao-chui-o-trabalho-infantil-nas-fronteiras/>. Acesso em: 24 mar. 2014.

${ }^{10}$ Para Bono (2009), antes da análise linguística dos MDs é importante breve abordagem acerca do gênero textual que veicula o fenômeno. Além disso, as primeiras questões dessa proposta atêm-se à classificação tradicional do "mas". Além disso, os temas transversais e/ou sociais podem ser o ponto de partida para a contextualização das propostas base para a análise linguística.
} 
e. Quem seria o emissor de cada um?

f.. Resuma a mensagem principal, em seguida, enumere argumentos contra o tema.

2. Observe a relação estabelecida pela conjunção "mas" na sentença "pra ti eu não tenho, mas tu deixas o teu filho aqui que ele pode fazer caixinha'. Com base na classificação da Gramática Normativa a relação semântica estabelecida seria:
I. a. aditiva
b. explicativa
c. adversativa d. alternativa
e. conclusiva

II. Por quais outras conjunções poderia ser substituída?

3. Apresente argumentos que possam se opor a cada item apresentado. Faça uso de conjunções coordenativas adversativas para estabelecer a conexão entre os argumentos.

a. No texto afirma-se que há uma naturalização do trabalho infantil,

b. O trabalho infantil não é um caso isolado apenas ao Chuí,

c. O poder público tem detectado ocorrências de trabalho infantil em vários pontos do país,

4. Agora observe a relação estabelecia pela conjunção “mas” na tirinha de Mafalda. É possível constatar que essa relação refere-se a:

a. oposição entre a ideia expressa no primeiro quadrinho em relação ao segundo.

b. uma adição de ideias que a personagem realiza referindo-se à necessidade do trabalho.

c. função conclusiva, pois a conjunção abre a sentença de fechamento das ideias.

d. apresenta uma característica interativa na conversação, realizando a transição entre as atividades verbais dos quadrinhos.

5. Nem sempre a conjunção "mas" serve para opor ou contrastar ideias e argumentos (positivo/negativo e viceversa). Determine a seguir as frases ${ }^{11}$ em que não há sentido de oposição:

a. "Aqueles que têm um grande autocontrole, ou que estão totalmente absortos no trabalho, falam pouco. Palavra e ação juntas não andam bem. Repare na natureza: trabalha continuamente, mas em silêncio." (Mahatma Gandhi)

b. "Inveja-se a riqueza, mas não o trabalho com que ela se granjeia." (Marquês de Maricá)

c. "Não quero atingir a imortalidade com meu trabalho, mas sim não morrendo." (Woody Allen)

d. "Mas na profissão, além de amar tem de saber. E o saber leva tempo pra crescer." (Rubem Alves)

e. "Trabalho não mata. Mas vagabundagem nem cansa." (Millôr Fernandes)

6. O MD “mas” é um conectivo ou conjunção que pode assumir, por exemplo, uma função compensadora, com isso marcar discursivamente que os valores argumentativos seguem uma mesma direção, ou seja, não marca oposição (valores argumentativos em direção contrastante). Observe o exemplo a seguir:

O governo tem investido em políticas publicas contra o trabalho infantil, mas (em compensação) são necessárias mais iniciativas nesse sentido.

Com base no tema trabalho infantil, elabore um parágrafo argumentativo em que fique evidente a função compensatória do MD "mas".

7. Você sabia que é possível comparar utilizando o MD “mas”? Observe o exemplo a seguir:

É certo que no Brasil ainda há muito trabalho infantil, mas também isso acontece muito em países industrializados que recebem imigrantes ilegais.

11 Disponível em: <http://pensador.uol.com.br/frases_sobre_o_trabalho_infantil/> Acesso em: 24 mar. 2014. 
Ao usar a expressão "mas também" o sentido argumentativo não se refere à oposição entre as orações e sim, uma comparação, no caso do exemplo, entre a situação do Brasil e de países industrializados com relação ao trabalho infantil. Valendo-se desse recurso discursivo realize a conexão dos argumentos abaixo:

Argumento A

Trabalho infantil é crime

Argumento B

A lei prevê trabalho ao menor de idade em certas circunstâncias

\subsection{PROPOSTA ILUSTRATIVA II: O “MAS” NAS FRASES DE EFEITO EM REDES SOCIAIS}

Ao que parecem, as frases ${ }^{12}$ de efeito passaram a se constituir em um gênero textual-discursivo muito utilizado nas redes sociais de forma geral. Com o intuito de demonstrar o estado de espírito, provocar uma discussão ou mesmo garantir a interação nas redes, as frases de efeito parecem refletir as intenções dos internautas. Além disso, ora são sentenças de famosos, pensadores, artistas em geral, trechos de poemas, ora por criação própria, as frases de efeito podem vir acompanhadas por textos imagéticos alusivos. Somente num ato de busca com a expressão "frases de efeito nas redes sociais" é possível encontrar aproximadamente 942.000 resultados em 0,37 segundos.

De todo modo, muitas vezes tais enunciados apresentam uma linguagem carregada dos usos sociais em permanente mudança. Nesse aspecto, é possível observar que diferentes estratégias são utilizadas nas frases de efeito, estratégias essas que se referem às intenções ${ }^{13}$ discursivas dos usuários das redes sociais. Em suma, foram usadas por motivos determinados.

Desta forma, analisaremos algumas frases presentes nesse contexto, tendo em vista como foi realizado o encadeamento oracional e/ou discursivo. Vamos descobrir se o "mas" é apenas uma conjunção adversativa ou se está funcionando como um conector pragmático. Com essa análise, é possível descobrir as nuances dos usos desse conectivo.

Observe os dois textos ${ }^{14}$ a seguir utilizados por internautas diferentes e com propósitos diferenciados:

\section{Texto I}

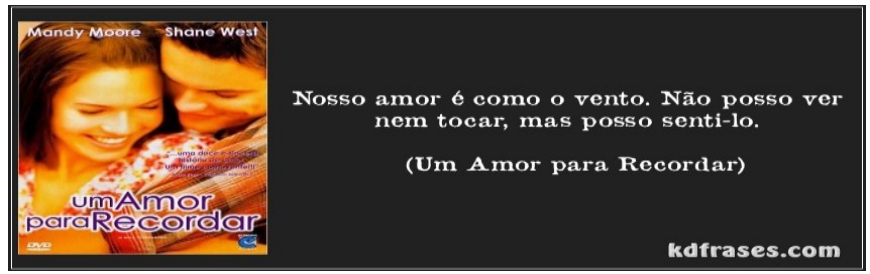

Texto II

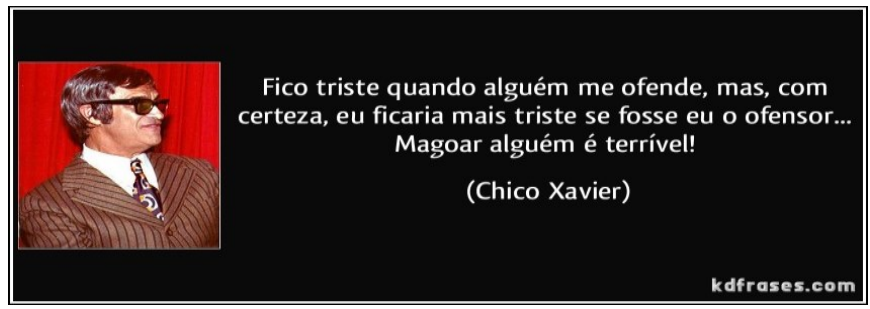

12 A concepção das frases como um gênero textual é discutida e caracterizada por Pedrosa (2005). Além da caracterização, a referida autora discorre sobre o papel do sujeito e sua posição nesse gênero.

${ }^{15}$ Com relação a esse conceito, as frases de efeitos podem ser caracterizadas, enquanto gêneros textuais, como atos de fala, uma vez que foram proferidos em determinado contex to de uso tendo certas intenções (AUSTIN, 1990).

${ }^{14}$ Disponível em: <http://kdfrases.com/frase/90844> Acesso em: 21 mar. 2014. 
1. É possível afirmar que nos dois textos a conjunção "mas" estabelece relação de oposição? Determine a relação semântica ${ }^{15}$ estabelecida pela conjunção dentro do quadro abaixo:

\begin{tabular}{|c|c|c|c|}
\hline & Argumento positivo / negativo & MAS & Argumento positivo / negativo \\
\hline Texto I & & & \\
\hline Texto II & & & \\
\hline
\end{tabular}

a. Ambos os textos podem ser colocados dentro dessa esquematização tradicional? Ou seja, os dois textos apresentam argumentos um oposto ao outro? Comprove.

b. No texto II o sentido da palavra "mas" parece não ser o habitual. Marque qual dos esquemas abaixo ilustra a relação estabelecida:

I. Argumento Negativo - mas - Argumento Negativo (relação opositiva com mesma intensidade argumentativa);

II. Argumento Positivo - mas - Argumento Negativo (relação aditiva com diminuição da força argumentativa); III. Argumento Negativo - mas - Argumento Negativo (relação aditiva com aumento da força argumentativa). 2. No texto I, com o uso da relação de oposição com o "mas" foi construída uma metáfora. Explique o efeito de sentido que o emissor intentou alcançar.

3. Tendo analisado os textos, é possível afirmar que ao proferir a frase presente no texto II, seu emissor Chico Xavier pretendia dizer algo contrário à primeira oração ou lançar um argumento mais forte para ter sua intenção entendida? Quais conclusões se podem tirar acerca do uso da conjunção "mas"?

4. Quais seriam os objetivos ou intenções gerais dos textos apresentados e analisados? Especifique.

O locutor informa sobre algo verídico

O locutor acredita na verdade do que afirma

O locutor quer que o interlocutor realize uma ação: responder a um pedido ou cumprir uma ordem

O locutor compromete-se com a realização da ação

O locutor exprime estados psicológicos através do enunciado proferido

O locutor validar/legitima uma determinada situação

5. Nos textos a seguir determine que tipo de relação discursiva que se estabelece dentro de cada enunciado. Em seguida comente qual o objetivo de cada texto e se de fato a conjunção "mas" marca ou não oposição.

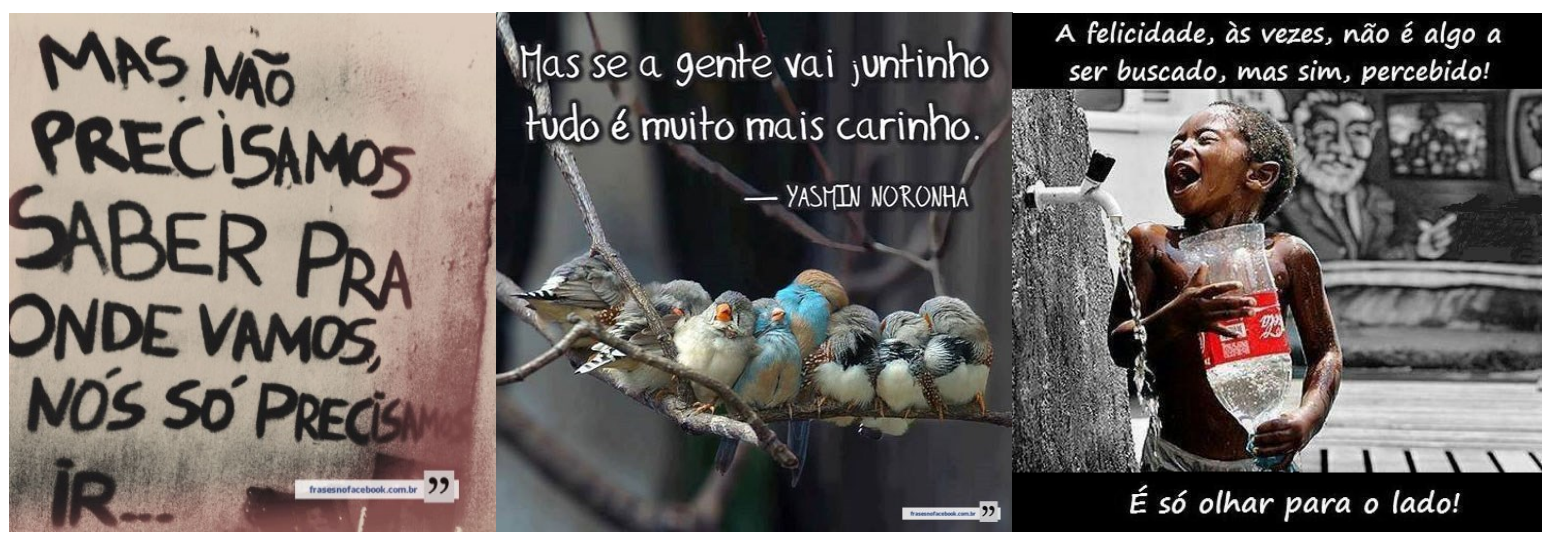

Fonte:< http://www.frasesparaofacebook.com/frases-de-musicas/mas-nao-precisamos-saber-pra-onde-vamos-1 1424/>. Acesso em: 22 mar. 2014. 15 Essa abordagem pressupõe que sejam trabalhadas as noções de força argumentativa (PORTOLÉS, 1998) na qual o discente deve ser capaz de
identificar a adversatividade, não somente pelo uso da conjunção, mas pela oposição dos argumentos, uma vez que o uso da conjunção por si mesma, como
pode-se constatar, nem sempre marca relação semântica de oposição (ALOMBA RIBEIRO, 2005).

Carmo \& Ribeiro (Os marcadores discursivos na educação básica) 


\section{CONSIDERAÇÕES FINAIS}

O estudo dos MDs pode favorecer o domínio discursivo, a capacidade de agir pela linguagem escrita, bem como ajudar os estudantes a processarem e conduzirem a própria linguagem e o próprio discurso de maneira mais consciente, coerente e eficaz. A pretensão maior de nossa agenda é incluir o estudo sistemático dos MDs, ampliando a perspectiva formal/normativa para uma abordagem pragmática, redimensionando seu status nos estudos gramaticais da Educação Básica.

O estudante da Educação Básica já dispõe de inúmeros recursos comunicativos, dado esse fato, convém que sejam bem direcionados na modalidade escrita, pela ampliação da descrição destas unidades, visando enriquecer seu emprego no texto escrito e levando em conta o plano discursivo da produção textual. De acordo os PCNs (1998), o ensino de língua não deve pautar-se somente na metalinguagem, que embora seja importante, não é suficiente para abranger o funcionamento da língua se não considerar os aspectos pragmáticos. Nessa perspectiva, sugere-se a criação de propostas didáticas para complementar essa abordagem mais tradicional, com o objetivo de também desenvolver a competência comunicativa dos estudantes.

A atividade apresentada visa apenas ilustrar as possibilidades dessa ampliação, funcionando como um instrumento para a compreensão do uso e da internalização das habilidades pretendidas. No modelo apresentado, os gêneros textuais e os temas de relevância sociocultural servem como suporte para o estudo da língua, partindo da abordagem tradicional e direcionando aos usos não previstos pela norma ou pela GT presente nos manuais didáticos e que podem favorecer ao domínio discursivo.

Outro fator importante concerne ao movimento metodológico interno que procura partir da descrição gramatical tradicional, provocar reflexão por meio de uma situação problema e, finalmente, apresentar novas funções para a unidade lexical em estudo.

Do ponto de vista do ensino de língua e dos aspectos metodológicos, a proposta elaborada para esse trabalho considera, além dos aspectos morfossintáticos que são trabalhados pela GT, o componente pragmático. Tal fator está evidenciado pelo recorte teórico, por considerar o plano discursivo e as práticas sociais de uso da língua materna.

\section{REFERÊNCIAS}

ALOMBA RIBEIRO, Maria D’Ajuda. Los conectores argumentativos en lós aprendices hispanohablantes de português. 2005. 271 f. Tese (Linguística Aplicada) - Departamento de Filologia, Universidade de Alcalá, Alcalá de Henares, 2005.

AUSTIN, John Langshaw. Quando dizer é fazer: palavras e ação. Trad. De Danilo Marcondes de Souza filho. Porto Alegre: Artes Médicas: 1990.

BAKHTIN, Mikhail. Estética da criação verbal. São Paulo: Martins Fontes, 1992 (1953).

BECHARA, Evanildo. Moderna Gramática Portuguesa. 37. ed. revista e ampliada. Rio de Janeiro: Editora Lucerna, 2004.

BONO, Mercedes Gallego. Marcadores discursivos em el proceso de composición del texto escrito: propuesta didáctica. 2009. 422 f. Tese (Doutorado) - Faculdade de Filología - Departamento de Las Lenguajes, Universidat de Valéncia, 2002. Disponível em: <http://roderic.uv.es/handle/10550/15315>. Acesso em: 21 mar. 2014.

BRASIL. Ministério da Educação. Plano de Desenvolvimento da Educação: Prova Brasil, ensino fundamental, matrizes de referência, tópicos e descritores. Brasília: MEC, SEB; INEP, 2008. 
BRASIL. Secretaria de Educação Fundamental. Parâmetros curriculares nacionais: terceiro e quarto ciclos do ensino fundamental: língua portuguesa / Secretaria de Educação Fundamental. Brasília: MEC/SEF, 1998. Disponível em: <http://portal.mec.gov.br/seb/arquivos/pdf/portugues.pdf>. Acesso em: 10 out. 2014.

DÁVILA, Cristina Maria. Decifra-me ou te devorarei: o que pode o professor frente ao livro didático? 2. ed. Salvador: EDUNEB; EDUFBA, 2013.

DIAS, Luiz Francisco. Estudo de classes de palavras: problemas e alternativas de abordagem. In: DIONISIO, Angela Paiva; BEZERRA, Maria auxiliadora (Org.). O livro didático de português: múltiplos olhares. 2.ed. Rio de Janeiro: Editora Lucerna, 2003, p. 126-138.

DISCINI, Norma; TEIXEIRA, Lucia. Perspectiva língua portuguesa. 2. ed. Volume 08. São Paulo: Editora do Brasil, 2012. (Coleção perspectiva $-8^{\circ}$ ano). $-9^{\mathrm{o}}$ ano).

Perspectiva língua portuguesa. 2. ed. Volume 09. São Paulo: Editora do Brasil, 2012. (Coleção perspectiva

FNDE. Dados estatísticos PNLD 2014. Disponível em: <http://www.fnde.gov.br/programas/livrodidatico/livro-didatico-dados-estatisticos>. Acesso em: 08 set. 2014.

FREITAG, R. M. K. Marcadores discursivos não são vícios da Linguagem. Interdisciplinar, São Cristóvão - SE, v. 4, n. 4, jul./dez. 2007. Disponível em:

<http://200.17.141.110/periodicos/interdisciplinar/revistas/ARQ_INTER_4/INTER4_Pg_22_43.pdf>. Acesso em: 19 set. 2013.

MENDES, Edleise. Aprender a ser e a viver com o outro: materiais didáticos interculturais para o ensino de português LE/L2. In: SHEYERL, Denise; SIQUEIRA, Sávio (Org.). Materiais didáticos para o ensino de Linguas na Contemporaneidade: contestações e proposições. Salvador: EDUFBA, 2012, p. 355-378.

MONTOLÍO, Estrella. Conectores de la lengua escrita, contraargumentatios, consegcutivos, aditivos y organizadores de la información. Barcelona: Ariel, 2001.

MORAIS, Maria da Felicidade Araújo. Marcadores da estruturação textual: elementos para a descrição do papel dos marcadores discursivos no processamento cognitivo do texto. Vila Real: Publito Artes Gráficas Ltda, 2011. Coleção Linguística 6. Disponível em:

<http://www.utad.pt/vPT/Area2/investigar/CEL/CelCollections/Documents/CEL_Lingu\%C3\%ADstica_6. pdf >. Acesso em: 19 Set. 2013.

NEVES, Maria Helena de Moura. Gramática de usos do português. São Paulo: Ed. UNESP, 2000. 4ª reimpressão.

OLIVEIRA, Ilana Gomes. O uso de marcadores discursivos em textos redacionais. 2012. 125f. Dissertação (Mestrado) - Programa de Pós-Graduação em Letras, Universidade Federal da Bahia, 2012. Disponível em: <http://www.repositorio.ufba.br/ri/handle/ri/8374>. Acesso em: 20 mar. 2014.

OLIVEIRA, Luciano Amaral. Coisas que todo professor de português precisa saber: a teoria na prática. São Paulo: Parábola Editorial, 2010.

PEDROSA, Cleide Emília Faye. Análise do sujeito no gênero textual "frases”. In: DIONÍSIO, A. P.; MACHADO, A. R.; BEZERRA, M. A. (Org.). Gêneros textuais e ensino. 4. ed. RJ: Lucerna, 2005. p. 194-207.

PORTOLÉS, José. Marcadores del discurso. Barcelona: Ariel S.A. , 1998. 
RISSO, Mercedes Sanfelice; SILVA, Giselle Machline de O.; URBANO, Hudinilson. Marcadores discursivos: traços definidores. In: KOCH, Ingedore G. Villaça (Org.).Gramática do português falado. 2. ed. rev. Volume VI: Desenvolvimentos. Campinas: Editora da Unicamp, 2002. p.21-103.

SILVA, José Manuel. Pragmática na didáctica do Português. 2006. Disponível em: <www.bocc.ubi.pt/pag/silvajose-manuel-pragmatica-didactica-portugues.pdf >. Acesso em: 14 Out. 2013.

SILVA, Sérgio Duarte Julião da. Marcadores discursivos no ensino de português-língua estrangeira (PLE) no Brasil. 2004. Dissertação (Mestrado) - Departamento de Letras Clássicas e Vernáculas da Faculdade de Letras e Ciências humanas da Universidade de São Paulo, São Paulo, 2004. Disponível em:

<www.teses.usp.br/.../DISSERTACAO_SERGIO_D_JULIAO_SILVA.pdf>. Acesso em: 20 out. 2014.

SUASSUNA, Lívia. Ensino de língua portuguesa: uma abordagem pragmática. 7.ed. Campinas, SP: Papirus, 2004. (Coleção magistério: formação e trabalho pedagógico).

TOKARNIA, Mariana. Livro didático ocupa segundo lugar dentre os mais lidos no Brasil. 2013. Disponível em: $<$ http://www.ebc.com.br/educacao/2013/02/livro-didatico-ocupa-segundo-lugar-dentre-os-mais-lidos-nobrasil >. Acesso em 08 set. 2014.

TRAVAGLIA, Luiz Carlos. Gramática e interação: uma proposta para o ensino de gramática no $1^{\circ}$ e $2^{\circ}$ graus. 3.ed. São Paulo: Cortez, 1997.

VAL, Maria da Graça Costa e. Atividades de produção de textos escritos em livros didáticos de $5^{\mathrm{a}}$ a $8^{\mathrm{a}}$ séries do ensino fundamental. In: ROJO, Roxane; BATISTA, Antônio Augusto Gomes (Org.). Livro didático de língua portuguesa: letramento e cultura da escrita. São Paulo, Campinas: Mercado das Letras, 2008. p. 185-210.

Recebido em 10/10/2014. Aprovado em 12/o5/15. 